\title{
Incidence of venous thromboembolism among patients with severe COVID-19 requiring mechanical ventilation compared to other causes of respiratory failure: a prospective cohort study
}

\author{
José Augusto Santos Pellegrini ${ }^{1} \cdot$ Tatiana Helena Rech $^{1,2} \cdot$ Patrícia Schwarz $^{1}$ - Ana Cláudia Tonelli de Oliveira ${ }^{3}$. \\ Tarsila Vieceli $^{3} \cdot$ Rafael Barberena Moraes $^{1,4} \cdot$ Leo Sekine $^{5,6} \cdot$ Marina Verçoza Viana $^{1}$ (D)
}

Accepted: 6 February 2021 / Published online: 18 February 2021

(c) The Author(s), under exclusive licence to Springer Science+Business Media, LLC part of Springer Nature 2021

\begin{abstract}
Previous studies have suggested that COVID-19 pneumonia is associated with an increased risk of venous thromboembolism (VTE). This study aimed to investigate the incidence of VTE among mechanically ventilated adults with COVID-19 pneumonia, compared to patients with respiratory failure related to other causes. Prospective study that enrolled critically ill adults with suspected COVID-19 pneumonia between June 2, 2020 and August 11, 2020. Critically ill adults with suspected COVID-19 pneumonia who required mechanical ventilation within $24 \mathrm{~h}$ after hospital admission were followed until death or hospital discharge. Sequential ultrasonography screening of the lower extremities and catheter insertion sites, as well as testing for plasma biochemical markers, were performed at the intensive care unit admission, day 3, day 7 , and day 14. The primary outcome was a composite of deep venous thrombosis, pulmonary embolism, and thrombosis at the central catheter insertion sites. We enrolled 70 patients, including 57 patients with COVID-19 and 13 patients without COVID-19, and all patients completed follow-up. The incidence of the primary outcome was higher among patients with COVID-19 than among patients with respiratory failure related to other etiologies $(36.8 \%$ vs. $0 \%, p=0.023)$. Multivariate regression analysis revealed that VTE was independently associated with a COVID-19 diagnosis (odds ratio: 6.28 , 95\% confidence interval: 1.19-68.07) and D-dimer concentration (1-ng/mL increase, odds ratio: $1.15,95 \%$ confidence interval: 1.05-1.30). The incidence of VTE was higher among critically ill mechanically ventilated patients, relative to among patients with respiratory failure related to other causes.
\end{abstract}

Keywords Thromboembolism · Respiratory insufficiency · Viral pneumonia · COVID-19 · Critical illness · Ultrasonography

Marina Verçoza Viana

maviana@hcpa.edu.br

1 Intensive Care Unit, Hospital de Clínicas de Porto Alegre, Ramiro Barcelos 2400, Porto Alegre, RS 90035-003, Brazil

2 Post-Graduate Program in Medical Sciences: Endocrinology, Universidade Federal Do Rio Grande Do Sul, Porto Alegre, RS, Brazil

3 Internal Medicine Division, Hospital de Clínicas de Porto Alegre, Porto Alegre, RS, Brazil

4 Post-Graduate Program in Medical Sciences: Pneumology, Universidade Federal Do Rio Grande Do Sul, Porto Alegre, RS, Brazil

5 Transfusion Medicine Division, Hospital de Clínicas de Porto Alegre, Porto Alegre, RS, Brazil

6 Post-Graduate Program in Medical Sciences, Universidade Federal Do Rio Grande Do Sul, Porto Alegre, RS, Brazil

\author{
Abbreviations \\ ARDS Acute respiratory distress syndrome \\ COVID-19 Coronavirus disease - 2019 \\ CTA Pulmonary computed tomography \\ angiography \\ DVT Deep venous thrombosis \\ ICU Intensive care unit \\ PE Pulmonary embolism
}

SARS-CoV-2 Severe acute respiratory syndrome coronavirus 2

SAPS $3 \quad$ Simplified acute physiology score 3

VTE 


\section{Highlights}

- Incidence of VTE was higher among patients with COVID-19 than among patients with respiratory failure of other etiologies (36.8\% vs $0 \%, p=0.023)$. Most of the VTE events occurred after the first week of ICU admission.

- COVID-19 is an independent risk factor for VTE in critically ill patients with respiratory failure (odds ratio: 6.28, 95\% confidence interval: 1.19-68.07) as well as D-dimer concentration (1-ng/mL increase, odds ratio: $1.15,95 \%$ confidence interval: $1.05-1.30$ ).

\section{Introduction}

Several studies have claimed that severe acute respiratory syndrome coronavirus 2 (SARS-CoV-2) causes viral pneumonia (COVID-19 pneumonia) that is associated with venous thromboembolism (VTE), which may be related to the interplay between vascular dysfunction, dysregulated inflammation, and immune thrombosis [1]. These phenomena might also be partially responsible for the severe hypoxemia seen in COVID-19-associated acute respiratory distress syndrome (ARDS) [2]. Unfortunately, VTE is common among patients with critical illness [3,4] and ARDS $[5,6]$, with incidences of $4-15 \%$ despite the use of routine thromboprophylaxis [7]. Necropsy studies have also revealed even higher incidences [8].

However, the exact VTE frequency is generally difficult to ascertain in ICU settings. This is due to various reasons including the absence of uniform screening at ICU admission to exclude patients with previous VTE, absence of systematic assessment with varying screening practices guided by clinicians' suspicion, and varying follow-up time [9]. Unfortunately, the available literature concerning patients with severe COVID-19 pneumonia does not fulfill the requirements to answer the exact incidence of VTE in COVID-19 patients. Furthermore, before changing welldeveloped, evidence-based approach to thromboprophylaxis in hospitalized critical patients, we need to be certain that the rate of VTE is indeed higher among similarly ill patients who do not have COVID-19 [10].

Therefore, this prospective cohort study aimed to clarify whether the incidence of VTE was higher among critically ill mechanically ventilated adults with COVID-19 pneumonia, relative to among ventilated patients with respiratory failure related to other causes.

\section{Methods}

\section{Study design and participants}

Between June 2, 2020 and August 11, 2020, this prospective study enrolled consecutive critically ill adult patients who were admitted to the intensive care unit (ICU) of the Hospital de Clínicas de Porto Alegre, which is a 1000-bed tertiary teaching hospital in Brazil. Patients were considered eligible if they were $>18$ years old, admitted to the ICU with suspected or confirmed severe COVID-19 pneumonia, defined by the requirement of invasive mechanical ventilation within the first $24 \mathrm{~h}$ after ICU admission. The exclusion criteria were a diagnosis of thrombosis at ICU admission, previous use of anticoagulation therapy, pregnancy, anatomical impossibility to scan the lower extremities and death or discharge from the ICU within $48 \mathrm{~h}$ after admission. Potentially eligible patients were also excluded when the number of ultrasonography examinations exceeded the research team's capacity to perform scans (up to five scans per follow-up day). A daily screening of patients with either confirmed or suspected severe COVID-19 pneumonia admitted to a COVID-19-dedicated ICU was performed. If any eligibility criteria were not met, the reason was recorded, and the patient was then excluded.

All procedures performed were in accordance with the ethical standards of the national research committee and with the 1964 Helsinki Declaration and its later amendments. This study was approved by the ethics committee of the Hospital de Clínicas de Porto Alegre approved the study protocol (2020-0194). All participants or their legal representatives provided informed consent by phone. This study is reported according to the STROBE guidelines [11].

\section{Procedures}

The diagnosis of COVID-19 infection was based on results from polymerase chain reaction testing for SARS-CoV-2 using nasal swabs. Patients were grouped according to whether a positive result was obtained (the COVID-19 group) or whether two negative results were obtained (the control group).

Clinical and laboratory data were recorded for all enrolled patients via electronic medical records. The variables included age, sex, comorbidities, time from symptoms to the development of respiratory failure, reason for ICU admission, mechanical ventilation settings, use of sedatives and neuromuscular blocker agents, need for prone positioning, extracorporeal membrane oxygenation 
therapy, and renal replacement therapy. Disease severity was scored using the Simplified Acute Physiology Score 3 (SAPS 3) [12]. The anticoagulation protocol for patients with COVID-19 was enoxaparin $1 \mathrm{mg} / \mathrm{kg}$ subcutaneous once a day, unless there was renal insufficiency. Patients without COVID-19 received either enoxaparin $1 \mathrm{mg} / \mathrm{kg}$ subcutaneous once a day or unfractionated heparin $5000 \mathrm{IU}$ subcutaneous three times a day. For all other patients the standard anticoagulation protocol is 15000UI of low molecular heparin daily. Patients with chronic anticoagulation therapy were excluded and we recorded both the higher dose of anticoagulation throughout the hospital stay and the reason for therapeutic anticoagulation.

Ultrasonography scans were performed as scheduled on days 3,7 , and 14 , even after patients were discharged from the ICU to the ward, while they were still at the hospital. The researchers in charge of the scans (JASP, PS and ACTO) were senior physicians who are considered experts in pointof-care ultrasonography. Researchers performing the scans were aware of the COVID-19 status of the patients as soon as results from polymerase chain reaction testing for SARSCoV-2 using nasal swabs were available and the patients without COVID-19 were transferred to non-COVID ICUs. The ultrasound images were acquired using the Sonosite M-turbo system (Fujifilm Sonosite, Bothell, WA, USA) or the Philips Innosight system (Philips, Eindhoven, Netherlands) with a linear probe (5-10 MHz). Ultrasonography scans were performed as planned even after ICU discharge, while patients were still at the hospital. The patient was placed in the supine position and the bilateral common femoral, femoral, and popliteal veins were examined using B-mode. The attending physicians in charge of patient care were informed of the scan results, and any subsequent decisions regarding anticoagulation or further investigation were at their discretion. All patients were followed until hospital discharge or death (last follow-up September 4, 2020).

Blood samples were obtained for testing to determine plasma D-dimer, platelet, and fibrinogen concentrations at admission, day 3, day 7, and day 14 . D-dimer testing was performed via latex agglutination and elevated concentrations were defined as $>0.5 \mathrm{ng} / \mathrm{mL}$. Platelets were quantified via automated cell count and the normal range was defined as $150-400 \times 10^{3} / \mu \mathrm{L}$. Fibrinogen testing was performed via spectrophotometry and elevated concentrations were defined as $>400 \mathrm{mg} / \mathrm{dL}$.

\section{Outcomes and Statistical analysis}

The primary outcome was a composite of VTE, which included lower limb deep vein thrombosis (DVT), pulmonary embolism (PE), and thrombosis at the central catheter insertion site(s). The secondary outcomes were the cumulative incidences of each individual VTE event, as well as plasma concentrations of D-dimers, platelets, and fibrinogen. The presence of DVT was defined by the absence of complete compression of the investigated vessel, regardless of whether hyperechogenic clots were visualized. Pulmonary computed tomography angiography (CTA) was ordered at the discretion of the attending physician, and PE was defined as arterial occlusion with failure to enhance the entire lumen due to a large filling defect or a partial filling defect surrounded by contrast agent. A thoracic radiologist independently reviewed the diagnosis of $\mathrm{PE}$, and the cases were classified according to the approximate central location as main artery, lobar, segmental, or subsegmental. Scans were considered negative if adequate contrast and no filling defects were observed within the pulmonary artery.

Arterial thrombotic events (myocardial infarction or stroke) were considered exploratory outcomes and were adjudicated by two researchers (ACTO and THR). Myocardial infarction was defined by the presence of elevated troponin I ultrasensitive and at a least one of the following: new ischemic electrocardiogram, imaging evidence of new loss of viable myocardium or new wall abnormality in a pattern consistent with ischemic etiology, or the identification of a coronary thrombus by angiography or autopsy. Since all patients were mechanically ventilated at the study entry, stroke was defined based on the findings of the head CT (new hypoattenuation described by an independent radiologist). We considered only findings of acute or subacute stroke as events.

The required sample size was calculated to be 68 patients using $\mathrm{G}^{*}$ Power software (version 3.1) to detect a difference of $27 \%$ between the groups, with $90 \%$ power and an alpha error of $5 \%$. Data were presented as mean \pm standard deviation, median (interquartile range [IQR]), or number (percentage). Inter-group comparisons were performed using oneway analysis of variance, the Mann-Whitney test, or the Fisher test, as appropriate. Missing data were not imputed. To assess the diagnostic accuracy of D-dimer concentrations for predicting the composite outcome, we constructed a receiver operating characteristic curve using the nearest D-dimer concentration before the event of interest. Plots with smoothed lines were created to visually assess the changes in the biochemical measurements over time.

Logistic regression was performed with VTE as the outcome and covariates were included in the multivariate model based on univariate $\mathrm{p}$-values of $<0.1$. Results were presented as odds ratios (ORs) and $95 \%$ confidence intervals (CIs). A Cox regression analysis with mortality as outcome was used to calculate hazard ratios (HR). Firth's penalization method was used to reduce the small-sample bias ("nonevents" in the control group) of the maximum likelihood coefficient [13]. Statistical analyses were performed using R software (version 3.5.1, The R Foundation) 
and differences were considered statistically significant at p-values of $<0.05$.

\section{Structured review}

We searched the PubMed database for English reports regarding VTE among patients with COVID-19 using the terms "severe acute respiratory coronavirus 2", "COVID19", "coronavirus", "venous thrombosis", "pulmonary embolism" and "anticoagulants". We also manually screened the reference lists of the included studies to identify related reports. Frequency of VTE was extracted and summarized afterwards.

\section{Results}

\section{Study population}

A total of 374 eligible patients were admitted to the ICU with suspected or confirmed COVID-19-related acute respiratory failure during the study period, although 304 patients were excluded for the reasons presented in Fig. 1. Thirteen patients were also excluded because of the presence of VTE at admission, and 11 of these patients were diagnosed as having COVID-19. The study ultimately enrolled 70 patients, including 57 patients with COVID-19 and 13 patients without COVID-19.

The main characteristics of the study population are summarized in Table 1 . The majority of patients were male $(52.9 \%)$, the mean age was $56 \pm 15$ years, and the mean SAPS 3 score was $58.3 \pm 11.2$. Patients without COVID19 had a higher mean SAPS 3 score and a shorter time from symptom onset to ICU admission. Most patients $(n=68)$ received a low-dose heparin regimen for DVT prophylaxis or full anticoagulation therapy. Two patients (both without COVID-19) had contraindications for heparin use.

The in-hospital mortality rates were $43.9 \%$ for patients with COVID-19 and $23.1 \%$ for patients without COVID$19(p=0.257)$. Patients with COVID-19 had longer median lengths for ICU stay (21 days [IQR: 14-29 days vs. 8 days [IQR: $7-16.5$ days]], $p=0.004$ ) and hospital stay (26 days [IQR: $17-37$ days] vs. 21 days [IQR: $12-28$ days], $p=0.004)$. At the time of this report, 6 patients $(8.6 \%)$ were still in the ICU.

\section{Incidence of thrombotic events}

The cumulative frequencies of the primary composite outcome were $36.8 \%$ among patients with COVID-19 and $0 \%$ among patients without COVID-19 $(p=0.023)$ (Table 2). Twenty-seven VTE events occurred in 21 individuals and involved lower limb DVT (11 events) or thrombosis at catheter insertion sites (10 events). Twenty-two patients (31.4\%) underwent CTA (31.6\% of patients with COVID-19 vs. $30.8 \%$ of patients without COVID-19, $p=1.0$ ). Six patients with COVID-19 (10.5\%) had PE, including 4 cases that involved lobar or segmental PE and two cases that involved subsegmental PE. The distribution of VTE events during follow-up is shown in Fig. 2. A Cox regression with Firth's penalization showed no difference between groups (HR: 5.61, 95\% CI: 0.299-105.1).

We identified a total of $8(10 \%)$ arterial thrombotic events during the study period, 7 myocardial infarctions and one stroke. From them, $6(10.5 \%)$ arterial thrombotic events were
Fig. 1 Patient eligibility and enrollment

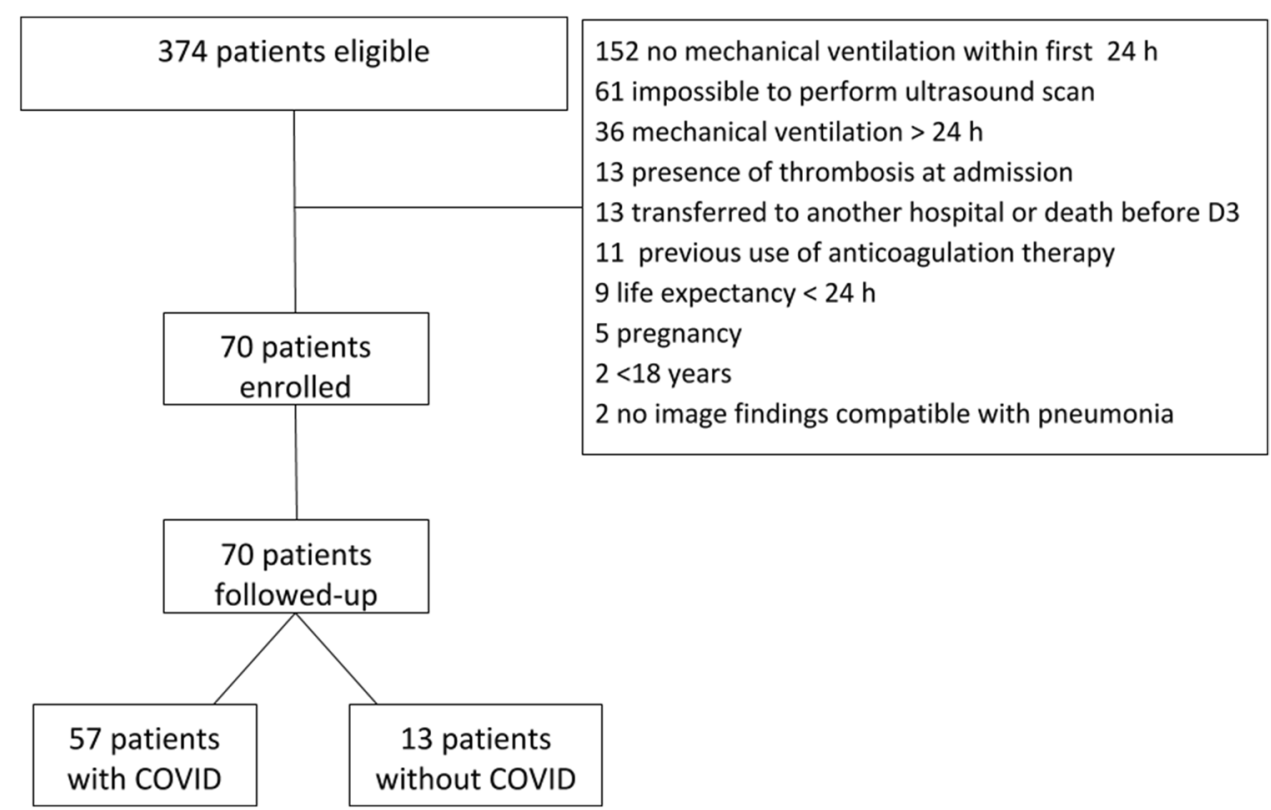


Table 1 The patients' baseline characteristics

\begin{tabular}{|c|c|c|c|c|}
\hline Characteristics & $\begin{array}{l}\text { All patients } \\
(\mathrm{N}=70)\end{array}$ & $\begin{array}{l}\text { Without COVID-19 } \\
(\mathrm{N}=13)\end{array}$ & $\begin{array}{l}\text { With COVID-19 } \\
(\mathrm{N}=57)\end{array}$ & $P$ \\
\hline Age (years) & $56 \pm 15$ & $57 \pm 20$ & $56 \pm 13$ & 0.754 \\
\hline Men, n (\%) & $37(52.9)$ & $7(53.8)$ & $30(52.6)$ & 1.000 \\
\hline $\operatorname{BMI}\left(\mathrm{kg} / \mathrm{m}^{2}\right)$ & $30.5 \pm 6.1$ & $29.2 \pm 7.1$ & $30.8 \pm 5.9$ & 0.427 \\
\hline SAPS 3 & $58.3 \pm 11.2$ & $65.6 \pm 12.3$ & $56.6 \pm 10.4$ & 0.009 \\
\hline \multicolumn{5}{|l|}{ Coexisting conditions } \\
\hline Hypertension, n (\%) & $36(51.4)$ & $7(53.8)$ & $29(50.9)$ & 1.000 \\
\hline Diabetes, n (\%) & $23(32.9)$ & $4(30.8)$ & $19(33.3)$ & 1.000 \\
\hline Heart failure, n (\%) & $23(32.9)$ & $2(15.4)$ & $1(1.8)$ & 0.152 \\
\hline Chronic kidney disease, $\mathrm{n}(\%)$ & $5(7.1)$ & $3(23.1)$ & $2(3.5)$ & 0.061 \\
\hline COPD, n (\%) & $3(4.3)$ & $0(0.0)$ & $3(5.3)$ & 0.931 \\
\hline Asthma, n (\%) & $9(12.9)$ & $2(15.4)$ & $7(12.3)$ & 1.000 \\
\hline AIDS, n (\%) & $2(2.9)$ & $1(7.7)$ & $1(1.8)$ & 0.813 \\
\hline Cancer, n (\%) & $4(5.7)$ & $2(15.4)$ & $2(3.5)$ & 0.316 \\
\hline Transplantation, n (\%) & $1(1.4)$ & $0(0.0)$ & $1(1.8)$ & 1.000 \\
\hline \multicolumn{5}{|l|}{ Reason for ICU admission } \\
\hline Acute respiratory failure, $\mathrm{n}(\%)$ & $68(97.1)$ & $11(84.6)$ & $57(100)$ & 0.037 \\
\hline $\mathrm{PaO}_{2} / \mathrm{FiO}_{2}$ ratio & $163[110-220]$ & $163[118-220]$ & $163[109.5-224.2]$ & 0.879 \\
\hline Days from symptoms to ICU admission & $7.00[4.00-8.75]$ & $3.00[2.00-4.50]$ & $7.00[4.75-9.00]$ & 0.001 \\
\hline Need for RRT, n (\%) & $16(28.6)$ & $2(20.0)$ & $14(30.4)$ & 0.783 \\
\hline Need for vasopressors, $\mathrm{n}(\%)$ & $48(70.6)$ & $9(69.2)$ & $39(70.9)$ & 1.000 \\
\hline Use of dexamethasone, $\mathrm{n}(\%)$ & $35(50.0)$ & $2(15.4)$ & $33(57.9)$ & 0.014 \\
\hline Use of neuromuscular blockers (n, \%) & $51(73.9)$ & $5(38.5)$ & $46(82.1)$ & 0.04 \\
\hline Platelets $\left(10^{3} / \mu \mathrm{L}\right)$ & $224 \pm 95$ & $190 \pm 87$ & $232 \pm 95$ & 0.148 \\
\hline D-dimer (ng/mL) & $1.50[0.94-4.07]$ & $2.68[1.61-6.94]$ & $1.38[0.86-3.95]$ & 0.091 \\
\hline Fibrinogen (mg/dL) & $654.0 \pm 186.9$ & $523.8 \pm 170.8$ & $674.2 \pm 182.8$ & 0.047 \\
\hline Use of heparin during hospitalization & & & & $<0.001$ \\
\hline Prophylactic UFH (n, \%) & $18(25.7)$ & $7(53.8)$ & $11(19.3)$ & \\
\hline Prophylactic LMWH (n, \%) & $47(67.1)$ & $3(23.1)$ & $44(77.2)$ & \\
\hline Therapeutic (n, \%) & $3(4.3)$ & $1(7.7)$ & $2(3.5)$ & \\
\hline Prone positioning (n, \%) & $28(41.2)$ & $2(15.4)$ & $26(47.3)$ & 0.074 \\
\hline $\operatorname{ECMO}(n, \%)$ & $4(6.1)$ & $1(7.7)$ & $3(5.7)$ & 1.000 \\
\hline
\end{tabular}

Data are presented as $\mathrm{n}(\%)$, mean \pm standard deviation, or median [interquartile range]. Comparisons between the groups were performed using one-way analysis of variance, the Mann-Whitney test, or the Fisher test, as appropriate. $P<0.05$ was considered significant

$B M I$ body mass index, SAPS Simplified Acute Physiology Score, COPD chronic obstructive pulmonary disease, ICU intensive care unit, RRT renal replacement therapy, $U F H$ unfractionated heparin, $L M W H$ low molecular weight heparin, ECMO extracorporeal membrane oxygenation

Table 2 Incidences of thromboembolic events in critically ill patients with and without COVID-19

\begin{tabular}{lllll}
\hline Outcomes & All patients $(\mathrm{N}=70)$ & $\begin{array}{l}\text { Without } \\
\text { COVID-19 } \\
(\mathrm{N}=13)\end{array}$ & $\begin{array}{l}\text { With } \\
\text { COVID-19 } \\
(\mathrm{N}=57)\end{array}$ & $P$ \\
\hline All thromboembolic events & $21(30.0)$ & $0(0.0)$ & $21(36.8)$ & 0.023 \\
Deep venous thrombosis & $11(15.7)$ & $0(0.0)$ & $11(19.3)$ & 0.193 \\
Thrombosis at catheter insertion site & $10(14.3)$ & $0(0.0)$ & $10(17.5)$ & 0.233 \\
Pulmonary embolism & $6(8.6)$ & $0(0.0)$ & $6(10.5)$ & 0.500 \\
Anticoagulation therapy during hospital stay & $20(28.6)$ & $3(23.1)$ & $17(29.8)$ & 0.884 \\
\hline
\end{tabular}

Data are presented as $\mathrm{n}(\%)$. Sequential ultrasonography screening was performed at the intensive care unit admission, day 3, day 7, and day 14. The bilateral femoral and popliteal veins were scanned, as well as all sites of catheter insertion. Pulmonary embolism was detected using computed pulmonary angiography, which was performed at the discretion of the attending physician. Comparisons between the groups were performed using the Fisher test and $\mathrm{P}<0.05$ was considered significant 
Fig. 2 Distribution of events during follow-up. Empty squares indicate deep venous thrombosis (lower limb or central catheter insertion site) and black circles indicate pulmonary embolism

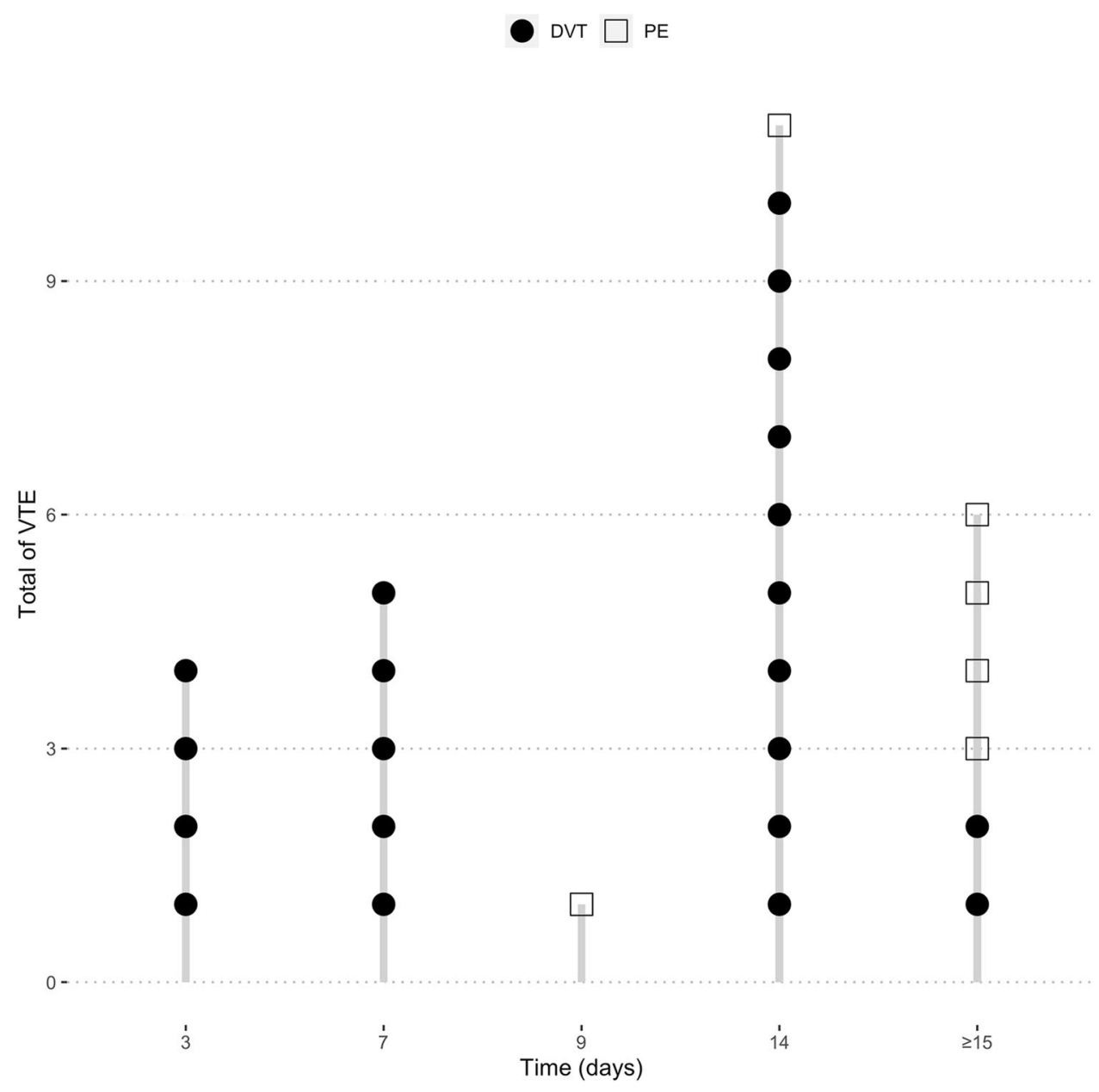

in patients with COVID-19 and $2(15.4 \%)$ were in patients without COVID-19 ( $\mathrm{p}=0.635)$.

Seven patients received anticoagulation therapy during the ICU stay for reasons other than confirmed VTE: extracorporeal membrane oxygenation installation (2 cases), acute coronary syndrome ( 2 cases), and preemptive full-dose heparin therapy based on a non-confirmed suspicion of VTE (3 cases, including 2 patients with COVID-19).

\section{Biochemical findings}

The median D-dimer concentrations at baseline were $1.38 \mathrm{ng} / \mathrm{mL}$ (IQR: $0.86-3.95 \mathrm{ng} / \mathrm{mL}$ ) for patients with COVID-19 and $2.68 \mathrm{ng} / \mathrm{mL}$ (IQR: $1.61-6.94 \mathrm{ng} / \mathrm{mL}$ ) for patients without COVID-19 $(p=0.09)$. Among patients with COVID-19, the D-dimer concentrations peaked on day seven and returned to near baseline on day 14. Using D-dimer concentrations during follow-up to predict the composite primary outcome provided an area under the receiver operating characteristic curve of $0.76(95 \% \mathrm{CI}$ : $0.64-0.88$ ). A cut-off value of $1.94 \mathrm{ng} / \mathrm{mL}$ provided $94 \%$ sensitivity, $57 \%$ specificity, a positive predictive value of $23.6 \%$, and a negative predictive value of $98.6 \%$ (Fig. 3a).

A logistic regression model fit using Firth's bias reduction method revealed that the primary composite outcome was independently associated with a COVID-19 diagnosis (OR: 6.28, 95\% CI: 1.19-68.07) and D-dimer concentrations (1-ng/mL increments, OR: 1.15, 95\% CI: 1.05-1.30). The SAPS 3 score was removed from the model because it was not a significant risk factor $(p=0.86)$.

The mean fibrinogen concentrations among patients with COVID-19 were significantly higher at baseline, relative to the group without COVID-19 $(674 \pm 182 \mathrm{mg} / \mathrm{dL}$ vs. $523 \pm 170 \mathrm{mg} / \mathrm{dL}, p=0.047)$. After an initial decrease, the mean fibrinogen concentrations remained at $>700 \mathrm{mg} /$ dL until day 14 . The platelet concentrations remained stable during follow-up and were similar between the study groups. Figure $3 \mathrm{~b}$ shows the changes in the biochemical parameters over time according to COVID-19 status. 

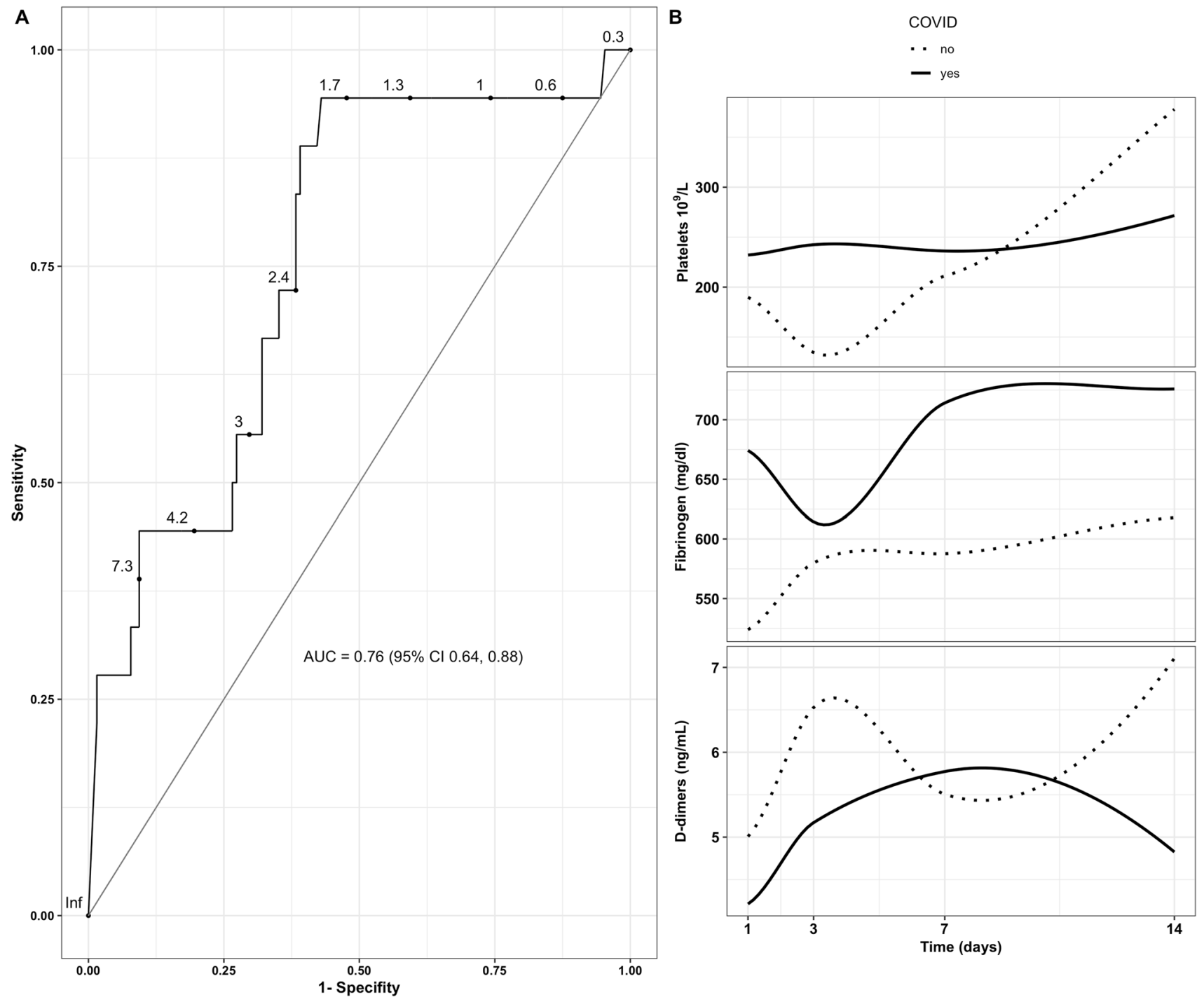

Fig. 3 Biochemical test results. a Receiver-operating characteristic (ROC) curve analysis of using D-dimer values to predict the incidence of the primary composite outcome. AUC, area under the ROC

\section{Structured review findings}

We identified 528 studies (Supplemental Digital Content.1), and we ultimately included 34 studies (Supplemental Digital Content.2) [14-47]. Five studies described necropsy results. Twenty-seven studies involved a retrospective design, and 29 studies were case series without a comparison group (nonCOVID patients). Among the five studies that included a control group, four studies used historical control groups. The aggregated frequency of VTE among COVID-19 cases was 35\% (95\% confidence interval [CI]: 24-48\%). However, the evidence from prospective studies precluded definitive conclusions regarding the relative incidence of VTE compared to critically ill individuals without COVID-19. A meta-analysis combining our results with those from five curve. b Changes in biochemical measurements over time shown using smoothed lines (top: platelets, $10^{9} / \mathrm{L}$; middle: fibrinogen, $\mathrm{mg} /$ $\mathrm{dL}$; bottom: D-dimers $\mathrm{ng} / \mathrm{mL}$ )

controlled studies (four retrospective studies and one prospective study) revealed that patients with COVID-19 had an increased risk of VTE (OR: 2.91, 95\% CI 1.69-5.02; $\left.I^{2}=44 \%\right)$.

\section{Discussion}

The main finding of this study is the higher cumulative incidence of VTE among mechanically ventilated patients with COVID-19 pneumonia, relative to among patients with acute respiratory failure related to other etiologies. The literature around COVID-19 is rapidly growing and to better assess the current knowledge of VTE frequency in COVID-19 patients, we performed a brief structured literature review. 
Our study compared with previous ones has clear methodological improvements: prospective design, similar comparison group, and a systematic approach to diagnose VTE. The cumulative frequency of VTE from our study (36.8\%) agrees with the aggregated frequency (35\%) from previous studies that were included in our systematic review. Hence, our results reinforce the previous findings with less bias than the available literature.

Bilaloglu et al. [18] performed a large retrospective study of VTE among patients with COVID-19 in New York City, and reported frequencies of $6.2 \%$ among hospitalized patients and $13.6 \%$ among critically ill patients. Helms et al. [27] performed a prospective study with historical controls and reported a VTE frequency of 18\% among critically ill patients. Despite excluding patients with VTE diagnosed at the ICU admission, we observed a higher VTE incidence, which might be explained by the greater diagnostic sensitivity of systematic ultrasonography assessments, and this incidence was independent of a clinical suspicion of thrombosis or D-dimer concentrations. Our results also agree with those from necropsy studies, which revealed even higher incidences of VTE. For example, Fox et al. [25] identified small thrombi in peripheral lung parenchyma sections from all individuals that they studied. When considered together, these results suggest that the calculated incidence of VTE among critically ill patients with COVID-19 might be dependent on the sensitivity or intensity of the diagnostic assessment.

Further discussion is warranted regarding the relative incidences of VTE among patients with COVID-19 pneumonia and patients with acute respiratory failure related to other etiologies. The high incidence of VTE in severe COVID19 might be attributable to the severity of critical illness with multiple organ dysfunctions. However, our patients without COVID-19 had higher SAPS 3 scores and similar $\mathrm{PaO}_{2} / \mathrm{FiO}_{2}$ ratios, relative to the patients with COVID-19. Different anticoagulation practices might partially explain different incidences of VTE; nevertheless, all of our patients with COVID-19 received either prophylactic or therapeutic heparin treatment.

Another possible explanation for the higher incidence of VTE among COVID-19 is the longer time from disease onset to ICU admission as well as the longer ICU and hospital stay of patients when compared with the non-COVID patients. The fact that most events occurred after the first week from ICU admission reinforces this hypothesis. It is important that physicians be aware this is a late complication of COVID-19. A Cox regression could not show a difference in risk when duration of exposure was taken into account, however this might be due to lack of power.

Despite the apparently poorer status of patients without COVID-19, the composite outcome only occurred among the patients with COVID-19. This might be related to changes in the interaction between the immune response and coagulation process, which could be mediated by molecular mechanisms that are specific to SARS-CoV-2 infection. Inflammation due to cytokine activation might lead to endothelial injury and activation of prothrombotic mechanisms in these patients [48]. The extensive damage caused by SARS-CoV-2 infection on surface ACE2 protein presenting cells leads to widespread release of a number of different cytokines (IL2, IL6, IL-7, IL-10, G-CSF, IP-10, MCP-1, MIP-1A and TNF- $\alpha$ ) leading to systemic inflammatory response syndrome. This phenomenon accelerates cell death in multiple tissues, and this cascade of inflammatory signalling eventually affects the microvascular system (which also expresses ACE2 protein), inducing the release of von Willebrand Factor and Factor VIII from Weibel-Palade bodies (a hallmark of endothelial injury), and resulting in generalised small vessel vasculitis and extensive microthrombosis, ultimately known as disseminated intravascular coagulation [49-51].

Elevated fibrinogen concentrations have been reported in patients with COVID-19 [27, 52]. This marker is involved in the pathophysiology of "immune thrombosis" [53] and a recent study revealed an association between IL- 6 concentrations and clot firmness using viscoelastic coagulation tests [52]. In contrast, patients with COVID-19 had a lower baseline D-dimer concentration, which has also been previously reported [27]. Nevertheless, this marker was fairly accurate for predicting VTE occurrence throughout the follow-up and was independently associated with the primary composite outcome.

The main strength of this study is the prospective cohort design with sequential ultrasonography assessments, which allowed us to evaluate the cumulative incidences of VTE among critically ill patients requiring mechanical ventilation according to their COVID-19 status. A comparison of contemporary cases with historical controls in previous studies is prone to bias, as the VTE diagnosis depends on a clinical suspicion, and a prospective systematic simultaneous comparison to a control group of patients is relevant. We included a well-defined population of critically ill individuals. The homogeneity of the studied patients increases the strength of the results, but also reduces the generalizability. Furthermore, our results reinforce the emerging knowledge that there is an increased risk of VTE in critically ill patients with COVID-19 and also that d-dimers have a high negative predictive value throughout the hospitalization.

Our study has several limitations. First, we were unable to scan all eligible patients because the case load during the outbreak exceeded the research team's scan capacity. However, we do not believe that eligible but excluded patients would be substantially different from the eligible and included patients, as an eligible patient's inclusion or exclusion was only based on the number of ultrasonography examinations that could be performed during a given 
day. Second, the small size of the control group limited the robustness of our comparisons, although the proportion of COVID-19 cases is likely related to the referral of patients with COVID-19 to our tertiary center in a regional health system network. Also, as the need of ICU beds grew, patients with negative test for COVID-19 were transferred to another hospital. Even though, there was only 13 patients and zero events in the group without COVID-19, using Firth's penalization method with VTE as outcome, it was possible to perform a multivariate logistic regression to reduce confounding bias. Third, although we did not identify VTE events in patients without COVID-19, one of these patients had computed tomography findings that suggested lung infarction, although CTA was not performed to confirm this possibility. Fourth, the CTA was performed at the discretion of the attending critical care team, and we did not perform systematic assessments to identify PE. Nevertheless, CTA indications followed international guidelines [54-56]. Fifth, patients received different heparin prophylactic regimens. However, patients with COVID-19 received LMWH more frequently than the control group, which could have introduced a conservative bias, as LMWH is the standard prophylactic heparin regimen in critically ill patients.

\section{Conclusion}

Patients with COVID-19 submitted to invasive mechanical ventilation had an increased risk of VTE, relative to patients with acute respiratory failure related to other etiologies. Further studies are warranted to clarify the pathophysiology underlying these thromboembolic events, the patients' prognoses, and the potential role of anticoagulation treatment in this setting.

Supplementary Information The online version of this article (https:// doi.org/10.1007/s11239-021-02395-6) contains supplementary material, which is available to authorized users.

Acknowledgements We thank Édison Moraes Rodrigues Filho for his assistance with the SAPS 3 data acquisition, Fundo de Incentivo à Pesquisa e Ensino, Hospital de Clínicas de Porto Alegre for funding and Editage (www.editage.com) for English language editing.

Author contributions JASP and MVV participated in the study conception and design, data acquisition, statistical analysis, data interpretation, and drafting and revising the manuscript. THR participated in the study conception and design, data acquisition, data interpretation, drafting and revising the manuscript. PS and RBM participated in the study design, data acquisition, data interpretation, and revising of the manuscript. TV, LS and ACT participated in the data acquisition, data interpretation, and revising the manuscript. JASP is the guarantor of this work, has full access to all data, and takes responsibility for the integrity of the data and the accuracy of data analysis.
Funding This study was supported by the Fundo de Incentivo à Pesquisa e Ensino, Hospital de Clínicas de Porto Alegre [2020-0194].

Data availability All available data are published in the current manuscript. Patient-level data that underlie the results reported in this article will be shared after de-identification (text, tables, figures, and appendices), beginning 6 months and ending 2 years after article publication, to researchers who provide a methodologically sound proposal for scientific research (with approval from an internal commission). Proposals should be directed maviana@hcpa.edu.br. A signed data access agreement will also be required.

Code availability The code used for the statistical analysis of the results reported in this article will be shared to researchers who provide a reasonable request Proposals should be directed maviana@hcpa.edu. br. A signed data access agreement will also be required.

\section{Compliance with ethical standards}

Conflict of interest On behalf of all authors, the corresponding author states that there are no competing interests.

Ethical approval All procedures performed were in accordance with the ethical standards of the national research committee and with the 1964 Helsinki Declaration and its later amendments. This study was approved by the ethics committee of the Hospital de Clínicas de Porto Alegre approved the study protocol (2020-0194). All participants or their legal representatives provided informed consent by phone.

Consent to participate All participants or their legal representatives provided informed consent by phone.

Consent for publication All authors agree with submission and publication in the Journal of Thrombosis and Thrombolysis.

\section{References}

1. Leisman DE, Deutschman CS, Legrand M (2020) Facing COVID-19 in the ICU: vascular dysfunction, thrombosis, and dysregulated inflammation. Intensive Care Med 46(6):11051108. https://doi.org/10.1007/s00134-020-06059-6

2. Marongiu F, Grandone E, Barcellona D (2020) Pulmonary thrombosis in 2019-nCoV pneumonia? J Thromb Haemost 18(6):1511-1513. https://doi.org/10.1111/jth.14818

3. Alhazzani W, Lim W, Jaeschke RZ, Murad MH, Cade J, Cook DJ (2013) Heparin thromboprophylaxis in medical-surgical critically ill patients: a systematic review and meta-analysis of randomized trials. Crit Care Med 41(9):2088-2098. https://doi. org/10.1097/CCM.0b013e31828cf104

4. Decousus H, Tapson VF, Bergmann JF, Chong BH, Froehlich JB, Kakkar AK, Merli GJ, Monreal M, Nakamura M, Pavanello R, Pini M, Piovella F, Spencer FA, Spyropoulos AC, Turpie AG, Zotz RB, Fitzgerald G, Anderson FA, Investigators I (2011) Factors at admission associated with bleeding risk in medical patients: findings from the IMPROVE investigators. Chest 139(1):69-79. https://doi.org/10.1378/chest.09-3081

5. Frantzeskaki F, Armaganidis A, Orfanos SE (2017) Immunothrombosis in acute respiratory distress syndrome: cross talks between inflammation and coagulation. Respiration 93(3):212225. https://doi.org/10.1159/000453002 
6. Greene R (1986) Pulmonary vascular obstruction in the adult respiratory distress syndrome. J Thorac Imaging 1(3):31-38. https:// doi.org/10.1097/00005382-198607000-00006

7. Duranteau J, Taccone FS, Verhamme P, Ageno W (2018) European guidelines on perioperative venous thromboembolism prophylaxis: intensive care. Eur J Anaesthesiol 35(2):142-146. https:// doi.org/10.1097/eja.0000000000000707

8. Tomashefski JF, Davies P, Boggis C, Greene R, Zapol WM, Reid LM (1983) The pulmonary vascular lesions of the adult respiratory distress syndrome. Am J Pathol 112(1):112-126

9. Mohamed MFH (2020) Caution is needed when reporting or pooling the prevalence of venous thromboembolism in critically Ill coronavirus disease 2019 patients. Crit Care Med. https://doi. org/10.1097/CCM.0000000000004693

10. Chowdhury JF, Moores LK, Connors JM (2020) Anticoagulation in hospitalized patients with covid-19. New Engl J Med 383(17):1675-1678. https://doi.org/10.1056/NEJMclde2028217

11. Vandenbroucke JP, von Elm E, Altman DG, Gøtzsche PC, Mulrow CD, Pocock SJ, Poole C, Schlesselman JJ, Egger M (2007) Strengthening the reporting of observational studies in epidemiology (STROBE): explanation and elaboration. PLoS Med 4(10):e297. https://doi.org/10.1371/journal.pmed.0040297

12. Moreno RP, Metnitz PG, Almeida E, Jordan B, BauerCampos PRA, Iapichino G, Edbrooke D, Capuzzo M, Le Gall JR (2005) SAPS 3- from evaluation of the patient to evaluation of the intensive care unit. Part 2: development of a prognostic model for hospital mortality at ICU admission. Intensive Care Med 31(10):1345-1355. https://doi.org/10.1007/s00134-005-2763-5

13. Heinze G, Schemper M (2002) A solution to the problem of separation in logistic regression. Stat Med 21(16):2409-2419. https:// doi.org/10.1002/sim.1047

14. Al-Samkari H, Karp Leaf RS, Dzik WH, Carlson JCT, Fogerty AE, Waheed A, Goodarzi K, Bendapudi PK, Bornikova L, Gupta S, Leaf DE, Kuter DJ, Rosovsky RP (2020) COVID-19 and coagulation: bleeding and thrombotic manifestations of SARS-CoV-2 infection. Blood 136(4):489-500. https://doi.org/10.1182/blood .2020006520

15. Artifoni M, Danic G, Gautier G, Gicquel P, Boutoille D, Raffi F, Néel A, Lecomte R (2020) Systematic assessment of venous thromboembolism in COVID-19 patients receiving thromboprophylaxis: incidence and role of D-dimer as predictive factors. J Thromb Thrombolysis 50(1):211-216. https://doi.org/10.1007/ s11239-020-02146-Z

16. Bemtgen X, Zotzmann V, Benk C, Rilinger J, Steiner K, Asmussen A, Bode C, Wengenmayer T, Maier S, Staudacher DL (2020) Thrombotic circuit complications during venovenous extracorporeal membrane oxygenation in COVID-19. J Thromb Thrombolysis. https://doi.org/10.1007/s11239-020-02217-1

17. Betoule A, Martinet C, Gasperini G, Muller P, Foucher S, Benner $\mathrm{P}$, Renard A (2020) Diagnosis of venous and arterial thromboembolic events in COVID-19 virus-infected patients. J Thromb Thrombolysis 50(2):302-304. https://doi.org/10.1007/s1123 9-020-02163-y

18. Bilaloglu S, Aphinyanaphongs Y, Jones S, Iturrate E, Hochman J, Berger JS (2020) Thrombosis in hospitalized patients with COVID-19 in a New York City health system. JAMA. https:// doi.org/10.1001/jama.2020.13372

19. Bompard F, Monnier H, Saab I, Tordjman M, Abdoul H, Fournier L, Sanchez O, Lorut C, Chassagnon G, Revel MP (2020) Pulmonary embolism in patients with COVID-19 pneumonia. Eur Respir J. https://doi.org/10.1183/13993003.01365-2020

20. Chen S, Zhang D, Zheng T, Yu Y, Jiang J (2020) DVT incidence and risk factors in critically ill patients with COVID-19. J Thromb Thrombolysis. https://doi.org/10.1007/s11239-020-02181-w

21. Demelo-Rodríguez P, Cervilla-Muñoz E, Ordieres-Ortega L, Parra-Virto A, Toledano-Macías M, Toledo-Samaniego N,
García-García A, García-Fernández-Bravo I, Ji Z, de-MiguelDiez J, Álvarez-Sala-Walther LA, Del-Toro-Cervera J, GaleanoValle F (2020) Incidence of asymptomatic deep vein thrombosis in patients with COVID-19 pneumonia and elevated D-dimer levels. Thromb Res 192:23-26. https://doi.org/10.1016/j.throm res.2020.05.018

22. Dolhnikoff M, Duarte-Neto AN, de Almeida Monteiro RA, da Silva LFF, de Oliveira EP, Saldiva PHN, Mauad T, Negri EM (2020) Pathological evidence of pulmonary thrombotic phenomena in severe COVID-19. J Thromb Haemost 18(6):1517-1519. https://doi.org/10.1111/jth.14844

23. Dubois-Silva Á, Barbagelata-López C, Mena Á, Piñeiro-Parga P, Llinares-García D, Freire-Castro S (2020) Pulmonary embolism and screening for concomitant proximal deep vein thrombosis in noncritically Ill hospitalized patients with coronavirus disease 2019. Intern Emerg Med. https://doi.org/10.1007/s11739-02002416-X

24. Edler C, Schröder AS, Aepfelbacher M, Fitzek A, Heinemann A, Heinrich F, Klein A, Langenwalder F, Lütgehetmann M, Meißner K, Püschel K, Schädler J, Steurer S, Mushumba H, Sperhake JP (2020) Dying with SARS-CoV-2 infection-an autopsy study of the first consecutive 80 cases in Hamburg, Germany. Int J Legal Med 134(4):1275-1284. https://doi.org/10.1007/s00414-020-02317-w

25. Fox SE, Akmatbekov A, Harbert JL, Li G, Quincy Brown J, Vander Heide RS (2020) Pulmonary and cardiac pathology in African American patients with COVID-19: an autopsy series from New Orleans. Lancet Respir Med 8(7):681-686. https://doi. org/10.1016/s2213-2600(20)30243-5

26. Fraissé M, Logre E, Pajot O, Mentec H, Plantefève G, Contou D (2020) Thrombotic and hemorrhagic events in critically ill COVID-19 patients: a French monocenter retrospective study. Crit Care 24(1):275. https://doi.org/10.1186/s13054-020-03025-y

27. Helms J, Tacquard C, Severac F, Leonard-Lorant I, Ohana M, Delabranche X, Merdji H, Clere-Jehl R, Schenck M, Fagot Gandet F, Fafi-Kremer S, Castelain V, Schneider F, Grunebaum L, Anglés-Cano E, Sattler L, Mertes PM, Meziani F (2020) High risk of thrombosis in patients with severe SARS-CoV-2 infection: a multicenter prospective cohort study. Intensive Care Med 46(6):1089-1098. https://doi.org/10.1007/s00134-020-06062-x

28. Klok FA, Kruip M, van der Meer NJM, Arbous MS, Gommers D, Kant KM, Kaptein FHJ, van Paassen J, Stals MAM, Huisman MV, Endeman H (2020) Confirmation of the high cumulative incidence of thrombotic complications in critically ill ICU patients with COVID-19: an updated analysis. Thromb Res 191:148-150. https ://doi.org/10.1016/j.thromres.2020.04.041

29. Koleilat I, Galen B, Choinski K, Hatch AN, Jones DB, Billett H, Indes J, Lipsitz E (2020) Clinical characteristics of acute lower extremity deep venous thrombosis diagnosed by duplex in patients hospitalized for coronavirus disease 2019. J Vasc Surg Venous Lymphat Disord. https://doi.org/10.1016/j.jvsv.2020.06.012

30. Lax SF, Skok K, Zechner P, Kessler HH, Kaufmann N, Koelblinger C, Vander K, Bargfrieder U, Trauner M (2020) Pulmonary arterial thrombosis in COVID-19 with fatal outcome: results from a prospective, single-center, clinicopathologic case series. Ann Intern Med. https://doi.org/10.7326/m20-2566

31. Llitjos JF, Leclerc M, Chochois C, Monsallier JM, Ramakers M, Auvray M, Merouani K (2020) High incidence of venous thromboembolic events in anticoagulated severe COVID-19 patients. J Thromb Haemost 18(7):1743-1746. https://doi.org/10.1111/ jth. 14869

32. Lodigiani C, Iapichino G, Carenzo L, Cecconi M, Ferrazzi P, Sebastian T, Kucher N, Studt JD, Sacco C, Alexia B, Sandri MT, Barco S (2020) Venous and arterial thromboembolic complications in COVID-19 patients admitted to an academic hospital in Milan, Italy. Thromb Res 191:9-14. https://doi.org/10.1016/j. thromres.2020.04.024 
33. Longchamp A, Longchamp J, Manzocchi-Besson S, Whiting L, Haller C, Jeanneret S, Godio M, Garcia Martinez JJ, Bonjour T, Caillat M, Maitre G, Thaler JM, Pantet R, Donner V, Dumoulin A, Emonet S, Greub G, Friolet R, Robert-Ebadi H, Righini M, Sanchez B, Delaloye J (2020) Venous thromboembolism in critically Ill patients with COVID-19: results of a screening study for deep vein thrombosis. Res Pract Thromb Haemost 4(5):842-847. https://doi. org/10.1002/rth2.12376

34. Marone EM, Rinaldi LF (2020) Upsurge of deep venous thrombosis in patients affected by COVID-19: preliminary data and possible explanations. J Vasc Surg Venous Lymphat Disord 8(4):694-695. https://doi.org/10.1016/j.jvsv.2020.04.004

35. Middeldorp S, Coppens M, van Haaps TF, Foppen M, Vlaar AP, Müller MCA, Bouman CCS, Beenen LFM, Kootte RS, Heijmans J, Smits LP, Bonta PI, van Es N (2020) Incidence of venous thromboembolism in hospitalized patients with COVID-19. J Thromb Haemost. https://doi.org/10.1111/jth.14888

36. Nadkarni GN, Lala A, Bagiella E, Chang HL, Moreno P, Pujadas E, Arvind V, Bose S, Charney AW, Chen MD, Cordon-Cardo C, Dunn AS, Farkouh ME, Glicksberg B, Kia A, Kohli-Seth R, Levin MA, Timsina P, Zhao S, Fayad ZA, Fuster V (2020) Anticoagulation, mortality, bleeding and pathology among patients hospitalized with COVID-19: a single health system study. J Am Coll Cardiol. https:// doi.org/10.1016/j.jacc.2020.08.041

37. Nahum J, Morichau-Beauchant T, Daviaud F, Echegut P, Fichet J, Maillet JM, Thierry S (2020) Venous Thrombosis among critically Ill patients with coronavirus disease 2019 (COVID-19). JAMA Netw Open 3(5):e2010478. https://doi.org/10.1001/jamanetwor kopen.2020.10478

38. Parzy G, Daviet F, Puech B, Sylvestre A, Guervilly C, Porto A, Hraiech S, Chaumoitre K, Papazian L, Forel JM (2020) Venous thromboembolism events following venovenous extracorporeal membrane oxygenation for severe acute respiratory syndrome coronavirus 2 based on CT scans. Crit Care Med. https://doi.org/10.1097/ ccm.0000000000004504

39. Patell R, Bogue T, Bindal P, Koshy A, Merrill M, Aird WC, Bauer KA, Zwicker JI (2020) Incidence of thrombosis and hemorrhage in hospitalized cancer patients with COVID-19. J Thromb Haemost. https://doi.org/10.1111/jth. 15018

40. Poissy J, Goutay J, Caplan M, Parmentier E, Duburcq T, Lassalle F, Jeanpierre E, Rauch A, Labreuche J, Susen S (2020) Pulmonary embolism in patients with COVID-19: awareness of an increased prevalence. Circulation 142(2):184-186. https://doi.org/10.1161/ circulationaha.120.047430

41. Ren B, Yan F, Deng Z, Zhang S, Xiao L, Wu M, Cai L (2020) Extremely high incidence of lower extremity deep venous thrombosis in 48 patients with severe COVID-19 in Wuhan. Circulation 142(2):181-183. https://doi.org/10.1161/circulationaha.120.04740 7

42. Tavazzi G, Civardi L, Caneva L, Mongodi S, Mojoli F (2020) Thrombotic events in SARS-CoV-2 patients: an urgent call for ultrasound screening. Intensive Care Med 46(6):1121-1123. https://doi. org/10.1007/s00134-020-06040-3

43. Trigonis RA, Holt DB, Yuan R, Siddiqui AA, Craft MK, Khan BA, Kapoor R, Rahman O (2020) Incidence of venous thromboembolism in critically Ill coronavirus disease 2019 patients receiving prophylactic anticoagulation. Crit Care Med. https://doi.org/10.1097/ ccm.0000000000004472

44. Whyte MB, Kelly PA, Gonzalez E, Arya R, Roberts LN (2020) Pulmonary embolism in hospitalised patients with COVID-19. Thromb Res 195:95-99. https://doi.org/10.1016/j.thromres.2020.07.025

45. Wichmann D, Sperhake JP, Lütgehetmann M, Steurer S, Edler C, Heinemann A, Heinrich F, Mushumba H, Kniep I, Schröder AS, Burdelski C, de Heer G, Nierhaus A, Frings D, Pfefferle S, Becker $\mathrm{H}$, Bredereke-Wiedling H, de Weerth A, Paschen HR, Sheikhzadeh-Eggers S, Stang A, Schmiedel S, Bokemeyer C, Addo MM,
Aepfelbacher M, Püschel K, Kluge S (2020) Autopsy findings and venous thromboembolism in patients with COVID-19. Ann Intern Med. https://doi.org/10.7326/m20-2003

46. Zermatten MG, Pantet O, Gomez F, Schneider A, Méan M, Mazzolai L, Hugli O, Bart PA, Papadimitriou-Olivgeris M, Alberio L, The C-ICCi (2020) Utility of D-dimers and intermediate-dose prophylaxis for venous thromboembolism in critically ill patients with COVID-19. Thromb Res. https://doi.org/10.1016/j.throm res.2020.08.027

47. Zhang L, Feng X, Zhang D, Jiang C, Mei H, Wang J, Zhang C, Li H, Xia X, Kong S, Liao J, Jia H, Pang X, Song Y, Tian Y, Wang B, Wu C, Yuan H, Zhang Y, Li Y, Sun W, Zhang Y, Zhu S, Wang S, Xie Y, Ge S, Zhang L, Hu Y, Xie M (2020) Deep vein thrombosis in hospitalized patients with COVID-19 in Wuhan, China: prevalence, risk factors, and outcome. Circulation 142(2):114-128. https://doi. org/10.1161/circulationaha.120.046702

48. Connors JM, Levy JH (2020) COVID-19 and its implications for thrombosis and anticoagulation. Blood 135(23):2033-2040. https ://doi.org/10.1182/blood.2020006000

49. Song JC, Wang G, Zhang W, Zhang Y, Li WQ, Zhou Z (2020) Chinese expert consensus on diagnosis and treatment of coagulation dysfunction in COVID-19. Mil Med Res 7(1):19. https://doi. org/10.1186/s40779-020-00247-7

50. Escher R, Breakey N, Lämmle B (2020) Severe COVID-19 infection associated with endothelial activation. Thromb Res 190:62. https:// doi.org/10.1016/j.thromres.2020.04.014

51. Marietta M, Ageno W, Artoni A, De Candia E, Gresele P, Marchetti M, Marcucci R, Tripodi A (2020) COVID-19 and haemostasis: a position paper from Italian society on thrombosis and haemostasis (SISET). Blood Transfus 18(3):167-169. https://doi. org/10.2450/2020.0083-20

52. Ranucci M, Ballotta A, Di Dedda U, Bayshnikova E, Dei Poli M, Resta M, Falco M, Albano G, Menicanti L (2020) The procoagulant pattern of patients with COVID-19 acute respiratory distress syndrome. J Thromb Haemost 18(7):1747-1751. https://doi. org $/ 10.1111 /$ jth. 14854

53. Nicolai L, Leunig A, Brambs S, Kaiser R, Weinberger T, Weigand M, Muenchhoff M, Hellmuth JC, Ledderose S, Schulz H, Scherer C, Rudelius M, Zoller M, Höchter D, Keppler O, Teupser D, Zwißler B, Bergwelt-Baildon M, Kääb S, Massberg S, Pekayvaz K, Stark K (2020) Immunothrombotic dysregulation in COVID-19 pneumonia is associated with respiratory failure and coagulopathy. Circulation. https://doi.org/10.1161/CIRCULATIONAHA.120.048488

54. Wiener RS, Schwartz LM, Woloshin S (2013) When a test is too good: how CT pulmonary angiograms find pulmonary emboli that do not need to be found. BMJ 347:f3368. https://doi.org/10.1136/ bmj.f3368

55. Konstantinides SV, Meyer G, Becattini C, Bueno H, Geersing GJ, Harjola VP, Huisman MV, Humbert M, Jennings CS, Jiménez D, Kucher N, Lang IM, Lankeit M, Lorusso R, Mazzolai L, Meneveau N, NíÁinle F, Prandoni P, Pruszczyk P, Righini M, Torbicki A, Van Belle E, Zamorano JL (2020) ESC Guidelines for the diagnosis and management of acute pulmonary embolism developed in collaboration with the European Respiratory Society (ERS). Eur Heart J 41(4):543-603 Doi: https://doi.org/10.1093/eurheartj/ehz405

56. Mayo J, Thakur Y (2013) Pulmonary CT angiography as first-line imaging for PE: image quality and radiation dose considerations. AJR Am J Roentgenol 200(3):522-528. https://doi.org/10.2214/ AJR.12.9928

Publisher's Note Springer Nature remains neutral with regard to jurisdictional claims in published maps and institutional affiliations. 